\title{
reviews
}

\section{Concepts of colour}

Color Vision: An Historical Introduction. By G. S. Wasserman. Pp. 224. (Wiley: New York and Chichester, UK, 1978.) $£ 13.40$.

ThOsE who study colour vision are very aware of the history of their field. There are two reasons for this. First, the topic is one that has recommended itself to the strongest intellects: Newton, Thomas Young, Maxwell and Helmholtz have left writings that set models of experimental elegance and theoretical clarity for the modern researcher. Second, the advancement of the field has depended on an instructive sequence of conceptual insights, which must be recapitulated by each fresh student. It is therefore very appropriate that Professor Wasserman should adopt an historical organisation in his intermediate-level textbook on colour vision.

As actual history, Wasserman's account is patchy and largely limited to expositions of the main printed sources. His summary of the relevant parts of Newton's Opticks is accurate and very clear; but his treatment of other early material is unashamedly based on secondary sources and he entirely omits mention of the trichromatists of the first half of the eighteenth century. His account of the contribution of Maxwell and Helmholtz is excellent, but then he spoils himself by recommending that the three-receptor theory of colour vision, which is widely referred to as the Young-Helnholtz theory (and which is almost certainly correct), should instead be eponymously linked with Newton and Maxwell. That Maxwell should enjoy more credit is fair; but to associate the theory with Newton is to confound the whole history of the field. The most fundamental fact about colour vision is that of trichromacy, the fact that only three variables are needed in a colour-matching experiment; and it is sometimes said that trichromacy is implicit in Newton's colour circle and centre-of-gravity rule. But (as Wasserman himself very clearly explains) by mixing three primary colours that lie on the circumference of Newton's circle, one can reach only that part of colour space enclosed by a triangle inscribed within the circle. Newton lacked the concept of imaginary primaries lying outside the colour circle; and he lacked that concept because he lacked in turn the idea of narrowly tuned transducers, supposing only that ". . . the Rays of Light in falling upon the bottom of the Eye excite vibrations in the Tunica Retina" (Qu. 12) and that these vibrations are "propagated through the solid, pellucid and uniform Capillamenta of the optic nerves into the place of sensation" (Qu. 23). The "several sorts of Rays" merely "make Vibrations of several bignesses, which according to their bigness excite Sensations of several Colours" (Qu. 13). As Newton understood neither the fact of trichromacy nor the trichromatic theory that was later introduced to explain it, I urge colleagues not to adopt Wasserman's suggestion that we should speak of the Newton-Maxwell theory.

The topics covered by Wasserman include colorimetry, colour blindness, component and opponent theories, zone theories, photometry, physiology. There are detailed discussions of the theories of Hurvich and Jameson and of Guth; of Land's experiments on colour contrast; of heterochromatic photometry; and of the early microspectrophotometric records. Wasserman has taken great pains to elucidate conceptual difficulties for students and this trouble is repaid by a very lucid text. I very much liked his discussion of imaginary primaries and his account of non-additivities of heterochromatic lights. There is a very helpful passage relating Granit's early reports of retinal 'dominators' and 'modulators' to the later electrophysiology.

But the book has two weaknesses. First, the coverage is unbalanced (the British come off especially badly). Rushton's reflection densitometry is dismissed as valueless in a sentence. Stiles' increment-threshold method passes entirely unmentioned, although the spectral sensitivities so derived are close to linear transformations of the colour-matching functions and (from this evidence and from microspectrophotometry) now seem likely to represent the sensitivities of the cones themselves. (Indeed, although the book is illustrated with a great number of spectral sensitivities, amazingly there is nowhere shown a set that resembles the ones likely to be correct.) Nothing is said of one of the most interesting developments of the last decade, Zeki's demonstration of areas in the prestriate cortex that seem to be specialised for the analysis of colour.

Second, Wasserman has some heresies of his own to press upon the unsuspecting student. Thus the chapter on colour blindness is quite out-of-date and misleading and the author perpetuates one of the most notorious conceptual errors of the field, that of supposing that anomalous trichromacy can be explained by giving abnormal weightings to the signals from the three cones of normal vision. There is a lot of dubious talk about twopeaked photo-pigment sensitivities in invertebrates and in vertebrates, without any mention to the student that invertebrate pigments may be bistable (the two states corresponding superficially to a rhodopsin and a metarhodopsin) or that the evidence for visually significant short-wave peaks in vertebrate pigments is very slight. The recent microspectrophotometric measurements of goldfish receptors shown on p189 do indeed exhibit secondary cis-peaks, but the goldfish pigments are based on vitamin $\mathrm{A}_{2}$ and Wasserman does not point out that the cis-peak of the long-wave human pigment (P565) would lie well below $400 \mathrm{~nm}$, at wavelengths complctely absorbed by the lens of the eye.

In summary, Wasserman's book is good in parts. Should this Curate's Egg be given to students? Only if accompanied by many, well placed pinches of salt.

J. D. Mollon is Lecturer in Experimental Psychology at the University of Cambridge, UK 